\title{
Multi-Country Analysis of Child Marriage Laws and Policy Instruments in Africa
}

\author{
UN Women East and Southern Africa Regional Office in Nairobi-Kenya \\ esaro.publications@unwomen.org
}

\begin{abstract}
This paper is informed by the findings and recommendations of the UN Women East and Southern Africa led Multi-Country Analytical Study of Legislation, Policies, Interventions and Cultural Practices on Child Marriage in Africa which undertaken in 2018. The study focused on Africa as a continent but synchronised into 10 study countries (Niger, Mali, Nigeria, Egypt, Ethiopia, Malawi, Mozambique, Tanzania, DRC and Morocco). It is undoubtable that child marriage is not only a regional challenge but also a global nightmare that every treaty, convention, protocol or agreement condemn. Succinctly, the Convention on the Elimination on All Forms of Discrimination against Women (CEDAW), the UN Convention on the Rights of the Child (CRC), the Beijing Declaration and Platform of Action, the Protocol to the African Charter on Human and Peoples' Rights on the Rights of Women in Africa, and the International Conference on Population and Development of 1994 are among the leading policy instruments that advance the human rights of children and thus are critical for ending child marriage. In this analysis, the paper underscores the critical role that such legal and policy frameworks perform in transforming toxic norms across the continent and beyond to deliver the human rights of women and girls with a particular focus on country legal frameworks and policies. In a snapshot, the paper focuses on relevant laws and regulations reported in the study including those that set the minimum age for marriage at 18 years for both/either girls and boys; requirements for birth and marriage registration; sexual violence and domestic violence laws; anti-corruption laws; and family status laws regulating marriage, divorce, custody, and inheritance.
\end{abstract}

Keywords: Child marriage, Child bride, age of marriage, prevalence, CEDAW, survivors, Bejing Platform for Action, UN Women, policy instruments, women and girls, constitution, customary laws, children, laws, religion, society, family code, criminal code, penal code, legal system, Africa, Niger, Mali, Nigeria, Egypt, Ethiopia, Malawi, Mozambique, Tanzania, DRC and Morocco.

DOI: $10.7176 / \mathrm{JCSD} / 51-07$

Publication date:September $30^{\text {th }} 2019$

\section{Regional Perspective}

The impact of child marriage on the rights of the child has been widely documented, and its elimination has become an international and regional priority. The practice is condemned by international and regional treaties, conventions, resolutions and platforms. Various agencies and stakeholders have designed and promoted agreements, conventions and protocols to promote interventions against the practice. The UN Convention on the Rights of the Child (CRC) and The Convention on the Elimination on All Forms of Discrimination against Women (CEDAW) are among the most important instruments since both are legally binding and many interventions are anchored in these two Conventions. The CRC and the CEDAW have recommended 18 years as the minimum age for marriage: accordingly, countries that are party to these instruments are required to legislate laws and policies to execute the recommendations. Several African countries had already committed to the Beijing Platform of Action in 1995 and thereafter the discussion on child marriage became part of the political agenda. According to the Platform of Action, countries were required to enforce laws on minimum age for marriage (Bejing Platform for Action, Chapter IV, 274e). Global and regional human rights agencies have long condemned the practice of child marriage on the grounds that since it violates girls' and women's' rights to education, health, and a life free from violence. There is an expanding literature on the harmful consequences of child marriage (see e.g. Singh and Samara 1996; Raj et al. 2009; Parsons et al. 2015) but limited knowledge about the processes facilitating child marriage (for notable exceptions see Scolaro et al. 2015; Prettitore 2015). The Protocol to the African Charter on Human and Peoples' Rights on the Rights of Women in Africa (article 6) was designed to hold African states to account on women's rights, including FGM and child marriage. The International Conference on Population and Development in 1994 (ICPD) also called on countries to eliminate 
child marriage and to enforce laws that ensure free and full consent, yet child marriage persists, especially in poor and rural parts of countries in the developing world.

The study appreciates that legal frameworks play a critical role in transforming norms and protecting the rights of women and girls. The study however cautions that the legal and policy frameworks are not sufficient drivers in themselves to realize the vision of ending child marriage but must be paired with effective enforcement and comprehensive prevention and protection efforts. Relevant laws and regulations reported in the study include those that set the minimum age for marriage at 18 years for both/either girls and boys; requirements for birth and marriage registration; sexual violence and domestic violence laws; anti-corruption laws; and family status laws regulating marriage, divorce, custody, and inheritance.

The study identified three levels of instruments that have been deployed against child marriage:- international agreements and commitments; national policies and laws directed at child marriage especially minimum age and consent; and tangential laws and policies that target other fundamental rights and protections for children. Over 32 countries across the continent, including eight countries listed in this brief, have taken some degree of action to address the issue. Two notable exceptions are of Egypt and Morocco who have not ratified the African Charter on Human and Peoples' Rights on the Rights of Women in Africa, while only Morocco among the study countries has not signed up to the AU Campaign to End Child Marriage in Africa. Further, seven of the countries of study have signed the Protocol to the African Charter on Human and Peoples' Rights on the Rights of Women in Africa, with the exception, as noted above, of Egypt and Morocco and, additionally, of Niger which has neither ratified nor deposited the Protocol with the African Union. They have also launched national action plans to eradicate child marriage and other harmful traditional practices in accordance with Article 16(1)-2 of CEDAW which commit states to eliminating all forms of violence against women through setting conditions of marriage such as minimum age, registration of marriage, and consent in marriage. However, discussions with AU representatives in Addis Ababa during the study revealed that, while almost all countries have laws and constitutional provisions aligned to key international instruments, there is a disconnect with the actual practices in those countries. For instance, although in many countries the law recognizes three forms of marriages, namely customary, religious and civil marriage, most of the legal obligations are imposed on civil marriages only thus making it difficult to enforce this age when marriages at an earlier age are condoned by custom or religion. ${ }^{i}$

Across the ten countries studied, there are laws and policies setting the minimum age for marriage and other protections for women and children with varying extent and effectiveness of implementation. It was evident that in the main, having the laws has made significant difference in awareness and practice of child marriage. They have affected and shaped public attitudes, perceptions and responses to child marriage. This happened by facilitating and requiring government follow - through and enabling citizen and court action for enforcement. Even when local enforcement is incomplete, laws may still have an impact by shaping the terms of debate and providing levers for civil society advocates.

African countries have so far set the minimum age of marriage at 18 years for both girls and boys, and sometimes above, as is the case in Algeria, Lesotho, Libya and Rwanda ${ }^{\mathrm{ii}}$. A review of laws and policies relating to child marriage in Africa (AUC/UN Women, 2017) found that out of 55 AU Member States, 41 Member States (75\%) have legal frameworks that put the minimum age of marriage at 18 or above for both girls and boys; however $20(49 \%)$ of these states have exceptions legalizing child marriage at an earlier age either with parental/guardian consent, judge approval and many more with the court/state's approval. A total of $12 \mathrm{Member}$ States $(22 \%)$ do not have a legal framework setting the minimum age at 18 years and above for both boys and girls, and six $(50 \%)$ of these have further exceptions reducing the age of marriage to as low as 10 years for girls. Another 14 (25\%) Member States have a different minimum age for boys and girls ranging from as low as 14 years for girls and 15 years for boys and two Member States have no minimum age for marriage. This brings the total number of states where child marriage is legalized to $34(62 \%)$. These are Member States with no minimum age for marriage, states without legal frameworks setting the minimum age at 18 years and above, and states where frameworks set the minimum age for marriage at 18 years and above exists, but have exceptions allowing child marriage, or where there are contradicting laws). ${ }^{\text {iii }}$ In the countries of study, all countries have legal and policy frameworks setting a minimum age of marriage. Seven countries $(70 \%)$ have set the minimum age at 18 years while only two countries (Mali and Tanzania) have exemptions on age of marriage specifically affecting females. Succinctly, Mali has an exemption setting a minimum age at 16 years for girls while Tanzania has an even lower age at 14 and 15 years for females respectively (in the Marriage Act (1971) which does not coincide with the provisions of the constitution which set the minimum age at 18 years for both sexes for Mali as the Constitution of Tanzania does not explicitly define the minimum age of marriage. However, males in the two countries are legally allowed to marry at a minimum of 18 years. 
In all the countries of study, the legal frameworks outline a series of requirements for a formal marriage - spousal consent without which marriage is rendered invalid; a minimum age for marriage (in most cases, 18 years); and civil registration. For example, in Niger, where over two thirds of girls between 15 and 19 years old are married (78\% in 2017), girls can be married at age 15 with parental permission. This in effect reduces the minimum age from the official limit of 21 to virtually any age permitted by the parents and the religious minister, thus exposing the loopholes in laws. ${ }^{\text {iv }}$ In some countries, the legal frameworks are buttressed by other policies which seeming tangential, extend beyond the penal codes or civil laws by instituting special rights and constitutional entitlements for women and children, and which in effect contribute to preventing child marriage. Such is the case with Malawi's school readmission policy that allows girls who became pregnant while in school to return after giving birth.

The study also noted that legal and policy loopholes are created by other civil policies especially those related to registration or births, marriages, divorce and deaths. In all the countries, there were weak registration systems that made it difficult to identify and legally prevent marriage involving under-age 'spouses' by allowing parents and marriage officials to fudge demographic data especially relating to the age of the brides. The study also found several legal exemptions that facilitate child marriage. An example is Mali where, although Article 281 of the Persons and Family Code sets the minimum age for marriages in Mali at 18 years for men and 16 years for women, exemptions on age can be granted in the office of the district administrator. Specific country and community conditions and practices make enforcement of laws and policies difficult and compromise the capacity and effectiveness of the structures charged with monitoring and implementing the laws. Such conditions and practices include corrupt officials and socio-culturally/religiously influenced judicial officers. In Egypt, the interpretation of Sharia laws limits the use of civil law. These conditions explain instances where abductors and rapists are facilitated to 'marry' their victims as was found common in Ethiopia, Nigeria and Niger.

Overall, as the AU review of laws established, in most countries the good laws have a range of exemptions within the law allowing for legalization of marriage of children under the age of 18 years. Furthermore, some Member States have conflicting laws with different minimum age for marriage applicable in civil, customary and religious courts. Customary and religious statutes and laws, although subservient to the civil laws in most countries, continue to sanction child marriages especially in rural areas and villages. This is particularly the case where civil laws provide ambiguity and lack of clarity on prohibitions or in countries where religious laws determine civil laws. ${ }^{\mathrm{v}}$

The study also established that several countries have not established robust national action plans despite being signatories of the AU Campaign to End Child Marriage. Among the 10 countries of study, only Morocco ${ }^{\mathrm{vi}}$ (representing 10\% of the study countries) had neither joined the campaign nor rolled out a national action plan against child marriage. This flows from the fact that the country was not part of the African Union until 2017. According to AU informants and country data, the challenge has been limited political will to invest state resources in implementing the action plans and prioritising child marriage elimination in the nation development agenda. Commitment at the continental level has not translated into national action plan; or in the case where costed action plans have been developed like Tanzania, they have not been translated into practice.

According to the AU, there are significant political barriers to rolling out national plans because national governments negotiate and compromise on the extent of enforcing laws with traditional leaders for fear of losing power. ${ }^{\text {vii }}$ Due to these and other factors, some countries, including Ethiopia and Nigeria, have developed some form of monitoring and evaluation mechanism for tracking child marriage. In Ethiopia for example, IMC worldwide has commissioned a three-year independent evaluation programme that includes a biannual verification of the End Child Marriage Programme funded by DFID. This aims at delaying child marriage for more than 200,000 girls in the Amhara part of Ethiopia. Similarly, Nigeria formed a Technical Working Group on Ending Child Marriage in 2015 under the Ministry of Women Affairs and Social Development to execute a holistic implementation, monitoring and evaluation of the existing laws and policies.

From the discussions and data gathered, efforts against child marriage have been benefiting from what may be considered tangential policies - policy instruments focused on achieving different developmental goals and SDGs such as education and health. In all the countries of study, there is commitment to universal education of all children and access to health services. Thus, as more girls attend compulsory schooling, they may avoid early marriage and thus raise the national age of marriage. Some countries like Malawi, Mozambique and Tanzania have return to school policies which, in certain cases, are rendered ineffective due to factors like the poverty often experienced by the families of victims of child marriage.

Other policies such as those on child rights and women empowerment through quota systems have also 
promoted an environment within which more girls can evade marriage early. The same applies for countries that have criminalized and adopted more radical interventions against child marriage such as Morocco that launched a law criminalizing rape and subsequent marriage of rape victims.

The study found that there is near universal commitment to the international instruments against child marriage across the ten countries and the continent. However, development and activation of national action plans remains a challenge. This calls for an alternative frame of reference which will emphasize a bottom-up approach - that is, focus on socio-cultural rather than legal reforms and more investment in activities that enhance implementation and enforcement of national laws. Effective enforcement requires clarity and elimination of possible ambiguities and loopholes by consolidating provisions on marriage under harmonized Act(s) for reference. Of critical interest here are the religious and customary provisions that redefine maturity and consent.

Case Study 1: Repeal of "Rapist Marry his Victim” law in Morocco.

Several respondents pointed out the importance of the Avaaz's 2014 petition that amended or repealed the "the rapist marry his victim" law in 2014. Prior to the petition and repeal, a painful event transpired. In 2012, Amina was raped at an age of 15 years and forced into marriage after her defiler, who was 25 years old then, traded in marriage for legal prosecution. The case may appear outdated or over publicized but the pain and the impact that it brought to the lives of many Moroccan girls will live to endure. Despite having to live in a nightmare, Amina was submerged in unending domestic violence and one day, she decided to end it all. She ingested rat poison and died.

Amina's death never became just any death but triggered a series of protests both in and outside Morocco prompting the state to repeal article 475 that closed rape cases on the basis of the rapist marrying the victim. The targeted provision of Article 475 of the Penal Code was finally amended on January 22, 2014. Today, Moroccan girls are no longer a slave of this law even though Amina would have loved to live and witness the change unfold.

Source: Field data

\section{Criminalization of Child Marriage}

In 2015, the United Nations Human Rights Council by consensus adopted the first-ever substantive resolution on child marriage embedded in the Sustainable Development Goals. An explicit target under Goal 5 in the new sustainable development agenda is to 'Eliminate all harmful practices, such as child, early and forced marriage.' The study reports that the adoption of SDGs and further to the African Union Campaign on Ending Child Marriage launched in 2015, nine countries of study have developed national initiatives, strategies and plans on

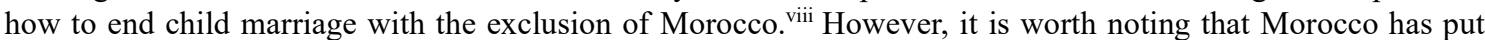
punitive fines on child marriage although it is not necessarily an effective deterrent. The law states that without prejudice to the more serious penal provisions, whoever compels others to marry by the use of violence or threats, is punished by imprisonment from six months to one year and a fine of 10,000 to 30,000 dirhams or one of these two penalties only. The sentence enacted is doubled when the victim is a minor. Ethiopia launched a national strategy and action plan to end child marriage in 2013. In 2015, Mozambique developed comprehensive strategies against child marriage and Other countries, including Malawi, have also undertaken legal reform to help end the practice. Setting 18 years or above as the legal age of marriage is a common step taken amongst a majority of the study countries.

Ethiopia is at one end of the continuum from criminalization to non-criminalization in the legal approach to child marriage in Africa. While 18 years is set as the legal age of marriage in the revised Family Code 2000, special provisions in the Criminal Code 2005 (Article 649) criminalizes child marriage. The Code explicitly states that marriage with someone below the age of eighteen years (apart for the exceptions allowed according to the Family Code) is punishable with imprisonment ranging from a minimum of three years marriage with minor below 18 years, or up to a maximum of seven years for marriage with minor below the age of thirteen years.

Despite setting the minimum age of marriage at 18 years in over $80 \%$ of the countries of study, $60 \%$ constituting Egypt, Morocco, Mozambique, Niger and Tanzania have not criminalized child marriage. These countries have legislated a minimum age of marriage at 18 years or above but have not criminalized child marriage. For Morocco, the law on EVAW, adopted in Morocco on February 14, 2018, does not criminalize child marriage but does create a new Article in the Penal Code which criminalizes forced marriages and doubles the sentence when 
the bride is a minor. ${ }^{\text {ix }}$ While the Moroccan government emphasized the importance of consent in marriage, it nonetheless makes the prosecution conditional on a complaint from the victim. This provision is particularly problematic in cases of child marriage as girls are particularly vulnerable to pressure from their spouse or family to drop complaints. Article 19 of Morocco's Family Code, amended in 2004, sets the age of marriage at 18 years, but derogations are possible under Articles 20 and 21 that allow judges to authorize child marriage, with or without the consent of the child's guardian. Articles 20 and 21 of the Family Code make no mention of the child's full, free and informed participation in marriage planning and execution. Article 21 requires the consent of a child's legal guardian, although judges may disregard a guardian's refusal to consent. The law also lacks appropriate safeguards for derogations, leaving broad discretion to judges. Exceptional circumstances are not defined in law, nor is there a requirement to take into account evidence of the adolescent's maturity. ${ }^{\mathrm{x}}$ Nonetheless, the articles require that Family Affairs Judges order a medical investigation and/or an inquiry into the social circumstances of the bride. In fact, the Office of the Chief Prosecutor issued a bulletin in March 2018, urging prosecutors in all Moroccan jurisdictions to introduce motions against granting permission for underage marriage. This bulleting particularly targeted circumstances in which the marriage seems to threaten the interests of the minor bride or groom. Additionally, it called on the judges to leverage court hearings, as per the legal provisions relevant to child rights, to raise the awareness of the underage children in marriage on the potential impact of marriage on their lives.

A further four of these countries (Niger, Mali, Mozambique and Tanzania) also provide exceptions to the law for instance upon parental consent or authorization by the court. Some make constitutional exceptions, typically for customary or religious law. In Tanzania for example, the Marriage Act (1971) allows girls at the age of 15-17 years to marry by parental consent, while boys may marry at 18 years. Girls may even marry at 14 years with court approval. Customary marriages are exempt from the law and this further opens up for child marriages below this age since girls typically are considered ready for marriage when they reach puberty. Only four countries including DRC, Ethiopia, Malawi and Nigeria have explicit provisions criminalizing child marriage in their countries.

Despite the fact that the majority of the countries of study have set 18 years as the minimum age for marriage for both males and females, weak enforcements has thwarted the positive impact of these policies. For instance, police in these countries may have little or no training to effectively handle child marriage cases and thus do not see it as their responsibility. On the same note, the principal documents, birth certificates, that can prove the ages of girls at marriage are rarely produced and verified at the time such marriages are officiated. For example, only $16 \%$ of children under five years in Tanzania are registered and worse still, only approximately half of them have received their birth certificates as shown by the anecdotal data that was analysed by the Tanzania National Bureau of Statistics and ICF Macro, Tanzania Demographic and Health Survey. ${ }^{x i}$ In order to bypass the legal requirements for a marriage, corrupt officials usually forge birth certificates after accepting bribes and thereby facilitate child marriage.

Essentially, corruption denies girls their accessibility to justice. In Tanzania, for instance, a police officer operating the Moshi Police Gender and Children's Desk informed the Human Rights Watch that there are a number of child rights related cases whose prosecutions are intentionally delayed or not concluded because child marriage perpetrators often bribe judges and prosecutors to adjourn or postpone them indefinitely. With such long delays, the victims together with their witnesses eventually give up coming to the courts and hence lose their cases. Jane K.'s (not her real names) assertion, "I want to report my husband's abuse to the police, but I do not have money to pay them to help me" cements the notion that corruption has badly affected the fight against child marriage and child rights abuse in general.

Additionally, all the countries of study have numerous overlaps in their customary, civil and religious laws and policies which often conflict each other. Similarly, religious leaders and communities who recognize child marriage as part of their religious or customary practices are always the architects of resistance against the enforcement of anti-child marriage legislations. 
Table 1: Minimum age of marriage- Country Laws

\begin{tabular}{|l|l|l|}
\hline Country & Girls & Boys \\
\hline DRC & 18 & 18 \\
\hline Egypt & 18 & 18 \\
\hline Ethiopia & 18 & 18 \\
\hline Malawi & 18 & 18 \\
\hline Mali & 16 & 18 \\
\hline Morocco & 18 & 18 \\
\hline Mozambique & 18 & 18 \\
\hline Niger & 18 (parental permission allows marriage by age & 18 \\
\hline Nigeria & $15)^{\text {xii }}$ & \multicolumn{2}{|l}{} \\
\hline Tanzania & 18 (18 & 18 \\
& $\begin{array}{l}\text { Marriage Act (1971) } \\
14 \text { (court consent); } \\
15 \text { (parental consent) } \\
\text { Constitution provides no minimum age for marriage }\end{array}$ & \\
\hline
\end{tabular}

Source: UN Women field data (2018)

\section{Multi Country Analysis of Policies and Legislations}

Many countries have set up laws and policies targeting prevention and eradication of child marriage. In others, original laws and policies have been strengthened with revisions aimed at consolidating various provisions in different sectors of the legal systems and at reducing any legal loop holes. The study identified different legal measures instituted in the countries which are having a significant impact on strengthening interventions against child marriage. While different countries have instituted laws and policies, some have made more progress in elaboration and implementation. There are still gaps in the legal/policy analysis which undermine the opportunity to use law/policy as a tool for protection of rights for children and women and for advancing gender equality.

\subsection{Dual Legal System}

Many countries have dual legal systems that recognises civil law and, separately, customary and religious law and practice. Some countries make customary laws subject to the Constitution while other countries treat customary laws as on a par with civil law. This has resulted in several countries having a general age of marriage specified by the civil law but then either allowing customary law to set a lower age for girls in certain circumstances or making age of marriage subject to customary or religious laws.

The study found that Tanzania, for instance, has a dual legal system whereby international legal instruments cannot be applied without appropriate ratification and domestication into local legal and policy frameworks. All key United Nations (UN) and African Union (AU) conventions on the rights of the child have been ratified. Moreover, the Law of the Child Act 2009 has, to a large extent, domesticated such international instruments. Apart from the child law, the country has enacted and formulated several pro-child rights laws, policies and guidelines. The other relevant laws include the Law of Marriage Act 1971; Penal Code, Cap. 16; and, the Education Act 1978. The policies and strategies include a recently formulated National Plan of Action to End Violence against Women and Children in Tanzania 2017-2022 (NPA 2017/2022). The Law of the Child Act 2009 sets the age of childhood as below 18 years. But, it does not invalidate Section 13 of the Law of Marriage Act 1971 which still legally sanctions marriage of girls aged 14 and 15 years under court orders and parents' permission respectively. Section 60A of the Education Act 1978 makes it unlawful for any person to marry a schoolgirl or schoolboy. The law provides that any person who contravenes this is liable to imprisonment of 30 years.

\subsection{Age of marriage in the Constitution}

In many countries, the age of marriage is not specifically mentioned either in the Constitution or in the marriage or family laws, or if stated, they are lower than the age of 18 years, contrary to what is stated in African and international treaties. Some countries have as a result embarked on law reform to live up to their international 
legal commitments as an important step and action.

In Malawi, the constitutional amendment of $14^{\text {th }}$ February 2017 that described a child as a person below the age of 18 years $^{\text {xiii }}$ is so far one of the greatest interventions in the legal framework to end child marriages. It for most purposes strengthened the Marriage, Divorce and Family Relations Act 2015 that had raised the legal marriage age for both boys and girls from 15 to 18 years $^{\text {xiv }}$ thereby clearing a major ambiguity previously existing over the legal age of marriage. There were now no longer any provisions for consent of marriage of a girl below the prescribed legal age as the constitutional amendment made it clear that any person below the age of 18 years was a child. Following the enactment, there was a clearly stated legal responsibility for protecting the girl child against harmful practices as provided for in the ACRWC and CEDAW that Malawi was party to and had ratified. ${ }^{\mathrm{xv}}$ The Malawi Gender Equality Act 2013 further provided for equal access to education and training as well as to other sectors of society for both boys and girls and set the stage for elimination of all forms of discrimination against girls and women including child marriage. In 2016, UNFPA supported the Ministry of Gender, Children, Disability and Social Welfare in setting up the gender implementation and monitoring plan in order to push the agenda for equality and elimination of discrimination among women and girls. ${ }^{\text {xvi }}$

In Malawi, key informants indicated that the return to school policy for teenage mothers who had dropped out of school due to pregnancy many subsequently being rescued from child marriages and willing to resume their education, as a right step in the right direction in addressing the problem of child marriages. The schools on their part have tried hard to provide a conducive learning environment for teenage mothers. The policy contributes to improving the indicators for completion and transition rates, especially among girls.

\subsection{Alignment of constitution, marriage laws and other sectoral laws}

One of the challenges where laws of marriage exists, is often contradiction with other laws or inconsistencies within the laws of marriages themselves. The key issues have arisen related to education policies and re-entry, and the age of consent related to health-related matters.

The Federal Government of Ethiopia has made significant steps towards eliminating child marriages by taking legislative actions against the practice and by promoting the wellbeing of girls and women through gender equality and women's empowerment. Of significance importance to this study, the Federal Government of Ethiopia incorporated women's rights and child protection issues in the 1994 Constitution as well as developing a women's policy in 1993. ${ }^{\text {xvii }}$ Under the Ethiopian Constitution, ${ }^{\text {xviii }}$ women are provided with rights and protections equal to those of men and, more specifically, women were granted rights to equality in marriage, maternity leave with full pay, participation and consultation in national development policies, and to acquire, administer, control, use and transfer property e.g. on land and inheritance.

In the year 2000, the Family Code was revised followed by revisions in the Criminal Code in 2005 to establish the minimum age of marriage at 18 years. The aim was to ensure that marriage and divorce procedures reflected the equality of the parties; and FGM/C was made illegal. Some amendments were made to domestic violence laws, defining it as a harmful traditional practice. 18 years was set as the minimum age of marriage for both boys and girls and betrothal was done away with. Child marriage was also criminalized in Article 648 of the Criminal Code with a penalty of three to seven years' jail term for perpetrators. In addition, several harmful cultural practices were criminalized e.g. FGM/C, infibulations, wife inheritance, as well as early and forced marriages. Despite these legal provisions being in place child marriages and FGM are still taking place. However, strong legal enforcement is gradually making headway in shifting the values and attitudes of the communities. ${ }^{\text {ix }}$

Key policy advancements to combat child marriage in Ethiopia were started in 2013 with the launching of the National Alliance to End Child Marriages and FGM/C, followed a month later with the launching of the National Strategy and Action Plan on Harmful Traditional Practices against Women and Children. The strategy defined harmful traditional practices as those that violate and negatively affect the physical, sexual or psychological well-being, human rights and socio-economic participation of girls, women and children. ${ }^{\mathrm{xx}}$ The aim of this strategy was to institutionalize national, regional and grassroots mechanisms by creating an enabling environment for the prevention and elimination of all forms of harmful cultural practices and ensure a multistakeholder approach in supporting women and children by prevention, protection and responsive services. To make this possible, a national platform on prevention and elimination of harmful traditional practices was launched in June 2015 under the Ministry of Women, Children and Youth Affairs (MoWCYA) with representatives from key stakeholders. ${ }^{x i}$ These policy initiatives, coupled with favourable legislative changes, have made it possible for many women and girls to records substantive advancements in education, access to health, wellbeing and as well as setting the stage for sustaining these gains among increasing numbers of women and girls. 
Case Study 2: Moroccan Moudawana has a big legal gap ${ }^{\mathrm{xxii}}$

The 2004 amendment of the Family Code ensured that the minimum marriage age moved to 18 years thus putting the country at the global threshold. This law applies to both girls and boys. The bill further directs that violators of the minimum marriage age, which is enshrined in the Children's Act, should be subjected to administrative punishments. This was indeed a celebrated move.

However, the celebrations lasted only a short while as perpetrators of child marriage spotted an opportunity in Articles 19 and 16. While Moudawana spells out that women have the right to choose their marriage partners and are only allowed to marry at age of 18 years, it also allows Family Judges to permit underage marriage under discretion. Surprisingly, statistics from the Ministry of Justice in Morocco (2014) showed that approximately $90 \%$ of marriage cases referred to them for their judgement were approved despite the couple, or at least one of them being below 18 years.

Rate of approval by judges of early marriage applications 2007-2013

\begin{tabular}{|l|r|r|r|r|r|r|r|}
\hline Year & $\mathbf{2 0 0 7}$ & $\mathbf{2 0 0 8}$ & $\mathbf{2 0 0 9}$ & $\mathbf{2 0 1 0}$ & $\mathbf{2 0 1 1}$ & $\mathbf{2 0 1 2}$ & $\mathbf{2 0 1 3}$ \\
\hline Approval & $86.79 \%$ & $88.48 \%$ & $90.77 \%$ & $92.21 \%$ & $89.56 \%$ & $85.99 \%$ & $85.46 \%$ \\
\hline Refusal & $10.72 \%$ & $11.05 \%$ & $8.59 \%$ & $7.79 \%$ & $10.44 \%$ & $14.01 \%$ & $14.54 \%$ \\
ed \\
Ire
\end{tabular}

which is not registered). It also emerged that Al Fatiha can occur even with the judge's refusal of the marriage. Eventually, the judge has no options than to recognize the marriage under Article 16 of the Moudawana which allows for a retroactive registration of such marriages.

Once a family affairs Judge has approved marriage of a child below 18 years, the decision cannot be appealed anywhere in Morocco. However, it is shocking to not that the Code allows parents or guardians to appeal a judge's decision barring child marriage. This has made the Code almost utterly ineffective in fighting child marriage in Morocco.

It also emerged that the process of awarding such under-age marriages are usually flawed. While Article 19 of the Family Code demands that a child's capacity to enter a union be assessed through a full medical and psychological test, respondents revealed that such tests are done by untrained doctors and are thus fake. Additionally, they do not focus on the life of a child beyond being a wife, a mother or a father.

As long as Article 19 of the Code is still intact in Morocco, the minimum age of marriage has very little significance. It is a case of as one hand gives, the other takes it back. In short, what the law prohibits in terms of marriage below a minimum age is offered in Articles 19 and 16 without constraint. As noted, approximately $90 \%$ of underage marriage cases referred to the courts get easy approvals.

Source: UN Women field data (2018) 
The Law of the Child Act 2009 defines a child as a person whose age is below 18 years. The Prisons Act 1967 considers a person below 21 years as a child. The Law of Contract, Cap. 433 defines a minor to be a person under 18 years. Under Section 11 of this contract law, a minor cannot enter into a contract. The Election Act 1985 also considers a child to be a person below 18 years. The Education Act 1978 prohibit marriage of the school children (regardless of the age); while, the Law of Marriage Act 1971 sanctions marriage of girls below 18 years. Furthermore, traditional and Sharia norms, which allow under age marriage of girls are sanctioned under the said marriage law. Therefore, the age of the girl child is contextual and has social and legal aspects leaving the girls vulnerable to decisions of their parents, guardians and even law enforcers.

The prescription of minimum age for marriage as 14 and 15 years, under court order and parents' consent respectively, was in force long before the inception of the Law of Marriage Act 1971. According to the participants in this study, the minimum age for marriage was one of the issues which the government put to be canvassed by the members of the public in its paper, Government Paper No. 1 of 1969.

The 15 years as minimum age was adopted under Section 13 of the Law of Marriage Act 1971 and it has remained unchanged to date (March 2018). Currently, as said before, a girl of 14 years can be married under a court order. The Law Reform Commission of Tanzania (LRCT) recommended an amendment of this provision to rise the age for marriage to 21 years in July 1986 and again in 1994. The minimum age has, however, remained unchanged even after ratification of the international legal instruments on the rights of the child; the enactment of the Law of the Child Act 2009 ten year ago did not change it.

The NGOs advocacy campaigns on legal/ policy reforms have so far remained in vain even the strategic litigation to challenge Section 13 of the Law of Marriage Act of 1971 has so far not yield victorious results as the government appealed against the 2016 decision of the High Court of Tanzania which nullified the said provision.

Source: UN Women field data (2018)

\section{Implications and Recommendations for Policy Interventions on Ending Child marriage in Africa}

4.1 Strengthen law and policy enforcement mechanisms: All African countries including the study countries have laws and policies on child marriage. In some countries, discrepancies exist between the existence of laws against child marriage and the enforcement of those laws. Enforcement of laws may be compromised by corruption, lack of accountability by responsible government officials and lack of resources to invest in public education and systems. The implication is that African governments should establish robust law enforcement mechanisms and systems that include public education, community-level monitoring and reporting of instances. It must also include mechanisms for referral, tracking and processing reported cases though to the eventual punishment of perpetrators, extraction of the children from the marriages and for post-marriage support systems including protection schooling and universal access to health services. Security agencies including community security chiefs and police should be supported with appropriate enforcement skills and awareness that aligns to a "do no harm approach" while ensuring they remain highly accountable for their actions in ending child marriage.

4.2 Strengthen prosecution and judicial systems and processes to ensure confidence in reporting and to provide deterrents amongst perpetrators: Laws that criminalise child marriage should guide the prosecution of child marriage cases without exemptions on the basis of third-party consent or consent from the judiciary. Similarly, girls who report child marriages should be accorded protection from the time they report these marriages to the point of prosecution in court, and thereafter as they seek reintegration into the community. Successful prosecution of these cases, where punitive measures are exercised, will provide deterrence to perpetrators while at the same time building confidence in the communities, and especially for girls, to report child marriages. Additionally, states should repeal any provision that enables perpetrators of rape, sexual abuse or abduction to escape prosecution and punishment by marrying their victims.

\subsection{Harmonization of laws and policies;}

a. Set the minimum age for marriage at 18 years in law for both males and females without any judicial exceptions- Judicial exceptions have been witnessed in many African countries including Mali, Niger and Tanzania. To adequately enforce these laws, capacity building should be targeted to all judicial officers and marriage registrars to understand the detrimental 
impact of child marriage, and the benefits in delaying marriage and enforcing laws against child marriage. The study found several legal exemptions that facilitate child marriage. An example is Mali where Article 281 of the Persons and Family Code sets the minimum age for marriages in Mali at 18 years for boys and 16 years for girls. Additional exemptions on age can be granted in the office of the District Administrator. Laws should be amended to ensure that there is no gender discrimination in law and that laws should be aligned to reflect the minimum age of marriage as 18 years for both boys and girls.

b. Amend laws and policies to ensure that customs, traditions and religion do not override constitutionally guaranteed and protected rights for women and children.

4.4 Strengthen registration and vital statistics to ensure legal compliance to eliminate child marriages: This includes birth, death, citizenship and marriage which enables planning for interventions, targeting and resourcing of services, and ensuring appropriate policies to prevent child marriage and support married children. In all the countries of study, there were weak registration systems that made it difficult to identify and legally prevent child marriages by allowing parents and marriage officials to fudge demographic data especially relating to the age of the brides. Countries need to prioritize and regularize the registration of births especially for individuals living in rural and remote areas, and of all types of marriages so that they are able to identify girls who are married below the age of 18 based on actual age and not the onset of puberty. Furthermore, states should identify and remove all physical, administrative, procedural and other barriers that impede access to registration and provide, where lacking, mechanisms for the registration of customary and religious marriages.

i. $\quad$ Develop national and regional accountability frameworks and mechanisms on ending child marriage:

a. Accountability through the Treaty Bodies: Reporting on the African Charter on the Rights and Welfare of the Child through the periodic report to the Committee by member states.

b. Report to the African Common Position (ACP) on Ending Child Marriage, through the biannual report to the African Union Summit. This is presented through the Presidential Champion on ending child marriage. While the ACP provides for a report once every two years, the nature and core indicators of such a report are yet to be defined.

c. The African Union Campaign on Ending Child Marriage has monitoring and evaluation as one of its key pillars. The work of the Campaign is to end child marriage through an integrated approach including stakeholder engagement -member states, UN agencies, regional economic communities, CSOs, media private sector, community-based organizations, champions and good will ambassadors, the Special Rapporteur on Ending Child Marriage among other players. However, there is no standardized, established and documented approach for such monitoring. To ensure that countries studied commit to specific targets and set indicators of progress, the study recommends developing accountability structures, frameworks and mechanisms for ending child marriage at national and regional level.

The accountability framework should be a tool to monitor country and regional progress towards the agreed commitments as set out in the AU agenda on ending child marriage whilst synergizing with sustainable development goal 5.3 on eliminating all harmful practices, such as child, early and forced marriage and female genital mutilations. There should be a coordination mechanism at the AU level to play a key role in the development and implementation of the accountability mechanism.

\section{Conclusion}

There is no doubt that numerous legislations and policy frameworks have been laid down to protect girls and women across Africa and specifically the countries under study. On the same note, there are several cultural norms and customary laws that operate side by side with the legal/policy frameworks. However, there is a huge inconsistency and disharmony between the two sets of legal systems (customary and mainstream legal systems), and this disconnect continuously perpetrate child marriage in Africa. Even in situations with better frameworks, implementation of such policies has been inconsistent with weak accountability mechanisms. This paper firmly calls for an urgent harmonization of customary laws with various existing legal/policy frameworks in order to end child marriage and related harmful practices against women and girls. 


\section{About UN Women}

The research is funded and led by UN Women East and Southern Africa Regional Office (UN Women is the UN Agency dedicated to gender equality and the empowerment of women. As a global champion for women and girls, UN Women was established to accelerate progress on meeting their needs worldwide. With a vision of equality enshrined in the Charter of the United Nations, UN Women works for the elimination of discrimination against women and girls; the empowerment of women; and the achievement of equality between women and men as partners and beneficiaries of development, human rights, humanitarian action and peace and security. UN Women also coordinates and promotes the UN system's work in advancing gender equality, and in all deliberations and agreements linked to the 2030 Agenda. The entity works to position gender equality as fundamental to the Sustainable Development Goals, and a more inclusive world. It supports UN Member States as they set global standards for achieving gender equality and works with governments and civil society to design laws, policies, programmes and services needed to ensure that the standards are effectively implemented and truly benefit women and girls worldwide. It works globally to make the vision of the Sustainable Development Goals a reality for women and girls and stands behind women's equal participation in all aspects of life. It is especially invested in its commitment to end all forms of violence including child marriage across the globe. UN Women envisions a world where societies are free of gender-based discrimination, where women and men have equal opportunities, where the comprehensive economic and social development of women and girls is ensured so that they can lead the change that they want to see, where gender equality and women's empowerment are achieved, and where women's rights are upheld in all efforts to further development, human rights, peace and security including ending discriminatory practices such as child marriage).

\section{Acknowledgement}

The paper has been developed for UN Women East and Southern Africa by;

1. Sadiq Ahamad Jilani Syed-Regional Programme Manager-Ending Violence Against Women and GirlsUN Women East and Southern Africa Regional Office.

2. Jack Onyisi Abebe-Regional Knowledge Management and Research Specialist-UN Women East and Southern Africa Regional Office.

3. Michael Faraday Awino-Regional Knowledge Management and Research Assistant- UN Women East and Southern Africa Regional Office.

The views expressed in this paper are those of the author(s) and do not necessarily represent the views of UN Women, the United Nations or any of its affiliated organizations.

\section{References}

\footnotetext{
${ }^{\mathrm{i}}$ Forum on Marriage and the Rights of Women and Girls Early Marriage and Poverty: Exploring links for policy and programme development (2003)

ii Ibid.

iii AU, 2017. Marriage Laws in Africa: A compendium of Laws from 55 Countries in Africa (Unpublished).

${ }^{\text {iv }}$ Arthur, Megan et al., 2014. Legal Protections against Child Marriage around the World. World Policy Analysis Centre/MachEquity, Los Angeles.

${ }^{v}$ AU, 2017 Ibid.

vi Supra, note 6.

vii AU key informant - Addis, $21^{\text {st }}$ February 2018

viii Supra, note 6.

${ }^{i x}$ Morocco: New Violence Against Women Law. Accessed at https://www.hrw.org/news/2018/02/26/morocco-newviolence-against-women-law on 16 May 2018.

${ }^{x}$ Amnesty International Submission for Morocco to the United Nations Human Rights Committee, 118th Session, 17 October - 14 November 2016

xi Tanzania National Bureau of Statistics and ICF Macro, "Tanzania Demographic and Health Survey 2010,” 2010, http://dhsprogram.com/pubs/pdf/FR243/FR243\%5B24June2011\%5D.pdf (accessed January 30, 2018), p. 27.

xii Save the Children, Child marriage in Niger, (Save the Children, 2017),

https://www.savethechildren.org.uk/content/dam/global/reports/advocacy/child-marriage-niger.pdf. (Accessed on March 6, 2018)

xiii http://www.unwomen.org/en/news/stories/2017/2/news-malawi-parliament-adopts-amendment-to-end-child-marriage
} 
${ }^{\text {xiv }}$ https://www.cmi.no/publications/5802-ending-child-marriages-new-laws-progress-malawi

${ }^{x v}$ ibid

xvi http://malawi.unfpa.org/en/news/2016-2020-gender-equality-act-implementation-plan-launched

xvii UNICEF (2016) Child marriage in Ethiopia: A review of the evidence and an analysis of the prevalence of child marriage in hotspot districts

xviii Article 35(4)

xix Supra, note 23

${ }^{x x}$ Supra Note 23

xxi Supra Note 23

xxii Approval rates sourced from the Official statistics from the Ministry of Justice and Liberties published in Family law: reality and perspectives, 10 years after the coming into effect of the Moudawana (May 2014) (Arab). 